Original Article - Clinical Science

\title{
Gram-negative endophthalmitis: A prospective study examining the microbiology, clinical associations and visual outcomes following infection
}

Louis J Stevenson MBBS, ${ }^{1}$ Rosie C.H. Dawkins MPH FRANZCO, ${ }^{1,2}$ Harsha Sheorey FRCPA, ${ }^{3}$ Myra B. McGuinness PhD, ${ }^{2}$ Andrew H. Hurley ${ }^{2}$ and Penelope J. Allen FRANZCO 1,2

1. Royal Victorian Eye and Ear Hospital, 32 Gisborne Street, East Melbourne, Victoria, Australia, 3002

2. Centre for Eye Research Australia, 32 Gisborne Street, East Melbourne, Victoria, Australia, 3002

3. Department of Pathology, St Vincent's Hospital Melbourne, 41 Victoria Parade, Fitzroy, Victoria, Australia, 3065

Correspondence: A/Prof PJ Allen, Royal Victorian Eye and Ear Hospital, 32

Gisborne Street, East Melbourne VIC, Australia

Email: pjallen@melbourneretina.com.au

Short running title: Gram-negative endophthalmitis

Received 13 November 2019; accepted 18 April 2020

Funding sources / Financial disclosure: None

Conflict of interest: None

\section{Data sharing and data accessibility statement}

This is the author manuscript accepted for publication and has undergone full peer review but has not been through the copyediting, typesetting, pagination and proofreading process, which may lead to differences between this version and the Version of Record. Please cite this article as doi: 10.1111/ceo.13768

This article is protected by copyright. All rights reserved. 
Data are available upon reasonable request made to the corresponding author. The Human Research Ethics Committee at the Royal Victorian Eye and Ear Hospital will be consulted throughout this process to ensure that all legal and ethical obligations are met.

\section{ABSTRACT}

I mportance: This is the largest Gram-negative endophthalmitis specific series and provides important evidence to guide management.

Background: Endophthalmitis is a sight-threatening emergency. Gram-negative infections are associated with poorer visual outcomes; however, there is limited literature pertaining to this uncommon condition.

Design: Prospective case series

Participants: All patients presenting with endophthalmitis to a tertiary institution over a twenty-year period.

Methods: Data were collected prospectively and entered into a registry. Patients with microbiological evidence of Gram-negative infection were included the analysis. Main outcomes measures: Final visual acuity, precipitating events, causative organisms, antibiotic sensitivity profiles, and risk factors for poor visual outcomes were reported.

Results: One hundred Gram-negative organisms were isolated in 97 eyes. Final visual acuity was worse than $6 / 60$ in 65 (67.0\%) eyes at follow-up and 29 (29.9\%) eyes were eviscerated or enucleated. Microbial keratitis $(26.8 \%, n=26)$ and Pseudomonas aeruginosa $(34.0 \%, \mathrm{n}=34)$ were the most common precipitating event and causative organism, respectively. Eight ( $8.0 \%)$ isolates were thirdgeneration cephalosporin resistant; of which, $7(88.0 \%)$ were sensitive to ciprofloxacin. Preceding microbial keratitis $(\mathrm{OR}=13.16, \mathrm{p}=0.015)$ or Pseudomonas 
aeruginosa infection ( $\mathrm{OR}=3.40, \mathrm{p}=0.045)$ were strongly associated with poorer visual outcomes (worse than 6/60).

Conclusions and relevance: Visual outcomes following Gram-negative endophthalmitis are extremely poor, with almost $30 \%$ of patients being eviscerated or enucleated. A majority of ceftazidime resistant organisms are sensitive to ciprofloxacin, providing evidence to support the empirical use of quinolones. Clinicians should be mindful that infections secondary to Pseudomonas aeruginosa or microbial keratitis carry a particularly poor prognosis.

KEY WORDS: Endophthalmitis, Gram-negative bacterial infections, antibiotic resistance 


\section{INTRODUCTI ON}

Endophthalmitis is an ophthalmic emergency characterised by a profound intraocular inflammatory response, usually secondary to infection. It is relatively uncommon but has the potential to cause rapid permanent vision loss and is therefore considered an ophthalmic emergency. In the published literature, Gram-negative bacteria account for $10-24 \%^{1-6}$ of all endophthalmitis cases, representing a clinically significant entity, given their association with poorer visual outcomes. ${ }^{1,7-9}$

Worldwide, there is significant variability in the epidemiology and microbiology of Gram-negative endophthalmitis. For example, endophthalmitis secondary to Klebsiella pneumoniae overwhelmingly affects people who have resided in East Asia, ${ }^{10}$ while antibiotic resistance profiles are known to be geographically specific. ${ }^{6,} 11$ This poses a challenge to the clinical management of the condition and impedes efforts to address underlying causes and evaluate the appropriateness of treatment regimens.

This report uses prospectively collected data to detail the prevalence, precipitating events, causative organisms, antibiotic sensitivity profiles, visual outcomes and predictors of poor visual acuity associated with Gram-negative endophthalmitis over a 20-year period. To the best of the authors' knowledge, it represents the largest published series of Gram-negative endophthalmitis and is the first to do so since $1992 .{ }^{12}$

\section{METHODS}

This study uses data from the Victorian Endophthalmitis Registry, a prospective database of all endophthalmitis cases managed at the Royal Victorian Eye and Ear 
Hospital (RVEEH), East Melbourne, Australia. The RVEEH is the largest eye hospital in Australia and the tertiary ophthalmology referral centre for the state of Victoria. A majority of public cases of endophthalmitis, in addition to a large number of private referrals, are managed at the institution, and as such, almost all endophthalmitis cases within Victoria are recorded in the registry. Patient details are recorded in the database by medical staff at the time of admission. The completeness of the database is then periodically checked against medical admission coding data to ensure that cases have not been missed.

At the RVEEH, all cases of endophthalmitis are managed by the vitreoretinal unit which is staffed by 10 vitreoretinal surgeons, 8 of whom contribute to the on-call roster. The management of endophthalmitis is guided by a hospital protocol with patients initially receiving intravitreal vancomycin and ceftazidime.

Endophthalmitis was defined as a profound intraocular inflammatory response secondary to ocular infection. Inclusion criteria were: a clinical diagnosis of endophthalmitis, as determined by the managing vitreoretinal surgeon, between July 1997 and J une 2017, and identification of Gram-negative organisms on microscopy or microbiological culture of ocular specimens. Accepted microbiological specimens included vitreous and anterior chamber biopsies, evisceration or enucleation contents, retinal biopsies and corneal scrapings, if it was deemed that endophthalmitis occurred secondary to microbial keratitis. Cases of microbial keratitis with limited vitreous view were included at the discretion of the managing vitreoretinal surgeon in instances where the above criteria were satisfied, based on alternate clinical examination findings and investigations such as no perception of light visual acuity, presence of a relative afferent pupillary defect or vitreous opacities on B-scan ultrasonography. 
The following data were collected and are summarised in Table 1: Demographic data, examination findings, precipitating events, clinical risk factors and microbiology findings. In cases of bilateral endophthalmitis, where the same species of organism was cultured in fellow eyes, organisms were considered as separate isolates. Where possible, the date of final review was at least six months post discharge to allow sufficient time for intraocular inflammation to subside, and the final visual acuity (VA) to be realised. In instances where this was not possible, the date of final review was determined by the patient's last recorded visit. Where patients were followed up at institutions other than the RVEEH after discharge, treating doctors were contacted for missing clinical information.

Table 1: Summary of collected data

\begin{tabular}{|ll|}
\hline Demographic data & Age \\
& Sex \\
\hline Examination findings & Snellen visual acuity at presentation and \\
& follow-up \\
& Fundus visibility at presentation \\
& Presence of a relative afferent pupillary \\
& defect at presentation \\
\hline Precipitating events & Cataract surgery \\
& Glaucoma surgery \\
& Microbial keratitis \\
& Intravitreal injection \\
& Penetrating ocular trauma \\
& Endogenous infection \\
& Other intraocular procedures \\
\hline Clinical risk factors & History of diabetes \\
& Insulin use \\
\hline Microbiology findings & Causative organism: Gram stain and/or \\
& culture results \\
& Anatomical location of culture specimen \\
& Antibiotic sensitivity profile \\
\hline
\end{tabular}


Data were collected and managed using REDCap electronic data capture tools hosted at the Centre for Eye Research Australia (CERA), either primarily or migrated from older versions of electronic data storage and checked for accuracy. Once entered, data were again reviewed using medical records to verify their accuracy before being exported and analysed.

The association between each of the risk factors (age, fundus visibility, diabetes and visual acuity at presentation, causative organism, polymicrobial infection, resistance to third generation cephalosporins, relative afferent pupillary defect [RAPD], precipitating events, the number of intraocular injections of antibiotics, the use of systemic antibiotics and steroids, and the use of vitrectomy) and a poor visual outcome (final VA worse than 6/60) was investigated via univariable logistic regression.

Multiple imputation was implemented to reduce bias due to missing data on risk factors. Values were multiply imputed ( 25 imputed datasets) using fully conditional specification (also known as chained equations) with a univariate linear regression imputation model (for missing values of presenting visual acuity), ordinal logistic regression (for missing values of quantity of intraocular antibiotic injections) and binary logistic regression imputations models (for missing values of RAPD, fundus visibility at admission and diabetic status). In addition to the imputation variables, imputation models included admission year, age at admission, final visual acuity, cataract as the precipitating event, the presence of Pseudomonas aeruginosa and polymicrobial infection status. The models were not able to converge following the inclusion of the other categorical risk factors. Missing values of the outcome of interest, final visual acuity, were not imputed. All analyses were conducted using Stata/SE version 15.1 (College Station, Texas). 
Ethical approval for this project was granted by the Human Ethics Research Committee at the RVEEH, East Melbourne, Australia and the research was conducted in accordance with the Declaration of Helsinki.

\section{RESULTS}

Ninety-seven eyes from 95 patients, representing 93 (97.9\%) unilateral and 2 (2.1\%) bilateral cases, were included. There were $58(61.1 \%)$ males and 37 (38.9\%) females, with a mean age of 73.4 years (SD $=15.6)$. In the same time period 1045 eyes, from 1037 patients, presented with endophthalmitis of any cause. Gram-negative bacteria were therefore isolated in $9.3 \%$ of eyes, and $9.2 \%$ of patients with endophthalmitis over the study period, with an incidence of 4.85 eyes and 4.75 patients affected per year.

One hundred Gram-negative organisms were isolated. These are summarised in Table 2. Pseudomonas aeruginosa was the most common, being isolated in over one-third of cases $(34.0 \%, n=34)$, followed by Haemophilus influenzae $(17.0 \%, n$ = 17), Moraxella spp. $(16.0 \%, \mathrm{n}=16)$ and Klebsiella pneumoniae $(9.0 \%, \mathrm{n}=9)$. Three organisms were identified as Gram-negative rods without further specification of their species. There was 1 case each of bilateral Pseudomonas aeruginosa and Haemophilus influenzae endophthalmitis.

Table 2: Gram-negative isolates and their relative frequencies (total $=100$ ).

\begin{tabular}{|ll|}
\hline Organism & $\mathrm{n}(\%)$ \\
\hline Pseudomonas aeruginosa & $34(34.0)$ \\
\hline Haemophilus influenzae & $17(17.0)$ \\
\hline Moraxella spp. & $16(16.0)$ \\
\hline Klebsiella pneumoniae & $9(9.0)$ \\
\hline Serratia spp. & $5(5.0)$ \\
\hline
\end{tabular}




\begin{tabular}{|ll|}
\hline Neisseria spp. & $3(3.0)$ \\
\hline Morganella morganii & $3(3.0)$ \\
\hline Escherichia coli & $3(3.0)$ \\
\hline Gram-negative rods (unidentified) & $3(3.0)$ \\
\hline Other & $7(7.0)$ \\
$\quad$ Sphingomonas paucimobilis & $1(1.0)$ \\
Elizabethkingia meningoseptica & $1(1.0)$ \\
Stenotrophomonas maltophilia & $1(1.0)$ \\
Ochrobactrum anthropi & $1(1.0)$ \\
Enterobacter cloacae & $1(1.0)$ \\
Citrobacter koseri & $1(1.0)$ \\
Pseudomonas fluorescens & $1(1.0)$ \\
\hline
\end{tabular}

Fourteen (14.4\%) eyes had polymicrobial infections. The causative organisms associated with these infections are summarised in Table 3.

Table 3: Summary of polymicrobial infections stratified by precipitating event

\begin{tabular}{|lll|}
\hline Case & Gram-negative organism(s) & Other \\
\hline Cataract surgery & $\begin{array}{l}\text { Haemophilus influenzae } \\
\text { Sphingomonas paucimobilis }\end{array}$ & $\begin{array}{l}\text { Staphylococcus epidermidis } \\
\text { Fusarium spp. }\end{array}$ \\
\hline 7 & $\begin{array}{l}\text { Pseudomonas aeruginosa } \\
\text { (not Staphylococcus epidermidis) }\end{array}$ \\
\hline 8 & $\begin{array}{l}\text { Pseudomonas aeruginosa } \\
\text { Gramnegative rod (not } \\
\text { specified) }\end{array}$ & \\
\hline 10 & Pseudomonas aeruginosa & Proponiobacterium spp. \\
\hline Glaucoma surgery & $\begin{array}{l}\text { Coagulase-negative Staphylococcus } \\
\text { (not Staphylococcus epidermidis) }\end{array}$ \\
\hline 5 & Haemophilus influenzae & $\begin{array}{l}\text { Actinomyces spp. } \\
\text { Streptococcus mitis }\end{array}$ \\
\hline 14 & Pseudomonas aeruginosa & \\
\hline Penetrating eye injury & $\begin{array}{l}\text { Pseudomonas fluorescens } \\
\text { Sphingomonas paucimobilis }\end{array}$ \\
\hline 3 & Stenotrophamonas maltophilia \\
\hline
\end{tabular}




\begin{tabular}{|lll|}
\hline \multicolumn{3}{|c|}{ Elizabethkingia meningoseptica } \\
\hline Microbial Keratitis & \\
\hline 6 & Octrobactrum anthropi & Staphylococcus epidermidis \\
\hline 9 & Pseudomonas aeruginosa & $\begin{array}{l}\text { Staphylococcus aureus } \\
\text { Corynebacterium spp. }\end{array}$ \\
\hline 13 & Pseudomonas aeruginosa & $\begin{array}{l}\text { Mixed coagulase negative } \\
\text { Staphylococci }\end{array}$ \\
\hline Endogenous infection & \\
\hline 1 & Klebsiella pneumoniae & Proponiobacterium acnes \\
\hline 11 & Neisseria meningitidis & Propionibacterium acnes \\
\hline 12 & Pseudomonas aeruginosa & Alternaria spp. \\
\hline
\end{tabular}

Vitreous cultures were positive in $64.9 \%(n=63)$ of eyes and negative in $35.1 \%$ ( $n=34)$ of eye. Aqueous cultures were positive in $37.1 \%(n=36)$ of eyes and negative in $62.9 \%$ ( $n=61$ ) of eyes. Six $(6.2 \%)$ eyes had a positive aqueous culture with a negative vitreous culture. Thirteen (13.4\%) eyes were diagnosed on the basis of positive intraocular cultures that were not vitreous or aqueous biopsies including six (6.2\%) patients with positive vitreous washings and 5 (5.2\%) with positive swabs of evisceration material taken intraoperatively. One (1.0\%) eye had a culture positive swab of intraocular discharge in the setting of a corneal perforation and 1 (1.0\%) eye was diagnosed following a positive culture using material obtained from a retinal biopsy. Sixteen (16.5\%) eyes did not have positive intraocular cultures; 14 (14.4\%) had Gram-negative bacteria cultured from corneal scrapes and 2 (2.1\%) had Gram-negative bacteria identified intraocularly on Gram stain only.

The antibiotic sensitivity profiles of isolated organisms are summarised in Table 4. Sensitivity profiles for third-generation cephalosporins were unavailable for 11 (11.0\%) organisms due to: antibiotics not being tested for Moraxella spp. (as there is no standardised break point to determine antibiotic sensitivity or resistance) (8.0\%, $n=8)$, organisms being identified on Gram stain only $(2.0 \%, n=2)$, and a failed antibiotic susceptibility test $(1.0 \%, n=1)$. Ciprofloxacin sensitivity profiles 
were unavailable for 9 (9.0\%) organisms due to: antibiotics not being tested $(7.0 \%$, $n=7)$ and bacteria being identified on Gram stain only (2.0\%, $n=2)$. For the remaining antibiotics (gentamicin, tobramycin, amikacin, and piperacillin/tazobactam), results were unavailable due to one organism (1.0\%) being identified on Gram stain only and a failed antibiotic susceptibility test (1.0\%), or antibiotics not beings tested (as antibiotic susceptibility testing is not standardised) in all other instances.

Table 4: Antibiotic sensitivity profiles

\begin{tabular}{|llll|}
\hline Antibiotic & $\begin{array}{l}\text { Sensitive } \\
\mathrm{n}(\%)\end{array}$ & $\begin{array}{l}\text { Resistant } \\
\mathrm{n}(\%)\end{array}$ & $\begin{array}{l}\text { Unavailable } \\
\mathrm{n}(\%)\end{array}$ \\
\hline $\begin{array}{l}\text { Third generation cephalosporin } \\
\text { (ceftazidime or ceftriaxone) }\end{array}$ & $81(81.0)$ & $8(8.0)$ & $11(11.0)$ \\
\hline Ciprofloxacin & $88(88.0)$ & $3(3.0)$ & $9(9.0)$ \\
\hline Gentamicin & $52(52.0)$ & $6(6.0)$ & $42(42 \%)$ \\
\hline Tobramycin & $59(59.0)$ & $2(2.0)$ & $39(39.0)$ \\
\hline Amikacin & $55(55.0)$ & $1(1.0)$ & $44(44.0)$ \\
\hline Piperacillin/tazobactam & $1(1.0)$ & $51(51.0)$ & $48(48.0)$ \\
\hline
\end{tabular}

A total of $8(8.0 \%)$ third-generation cephalosporin resistant organisms were isolated in $6(6.3 \%)$ patients. The clinical characteristics of these organisms are summarised in Table 5. 
Table 5: Clinical characteristics of third-generation cephalosporin resistant organisms

\begin{tabular}{|c|c|c|c|c|c|c|c|}
\hline Patient & Organism(s) & Year & Precipitating event & $\begin{array}{l}\text { Sensitive to } \\
\text { ciprofloxacin }\end{array}$ & $\begin{array}{l}\text { Ceftriaxone/ceftazidime } \\
\text { minimum inhibitory } \\
\text { concentration } \\
\text { (mg/L) }\end{array}$ & $\begin{array}{l}\text { Intravitreal antibiotic } \\
\text { administration }\end{array}$ & $\begin{array}{l}\text { Final visual } \\
\text { acuity }\end{array}$ \\
\hline 1 & $\begin{array}{l}\text { Pseudomonas } \\
\text { aeruginosa }\end{array}$ & 1997 & $\begin{array}{l}\text { Microbial keratitis in } \\
\text { nursing home resident }\end{array}$ & Yes & $>16$ & $\begin{array}{l}\text { Primary evisceration, no } \\
\text { intravitreal antibiotics } \\
\text { administered }\end{array}$ & Eviscerated \\
\hline $2^{\dagger}$ & $\begin{array}{l}\text { Stenotrophomonas } \\
\text { maltophilia } \\
\text { Elizabethkingia } \\
\text { meningoseptica }\end{array}$ & 1998 & $\begin{array}{l}\text { Penetrating eye injury } \\
\text { following tyre } \\
\text { explosion }\end{array}$ & $\begin{array}{l}\text { Inherently } \\
\text { resistant } \\
\text { Yes }\end{array}$ & $\begin{array}{l}>256 \\
>16\end{array}$ & $\begin{array}{l}\text { One intravitreal } \\
\text { injection } \\
\text { 1. Vancomycin, } \\
\text { ceftazidime }\end{array}$ & Unavailable \\
\hline 3 & $\begin{array}{l}\text { Ochrobactrum } \\
\text { anthropi }\end{array}$ & 1999 & $\begin{array}{l}\text { Microbial keratitis in } \\
\text { the setting of previous } \\
\text { penetrating } \\
\text { keratoplasty }\end{array}$ & Yes & $>16$ & $\begin{array}{l}\text { One intravitreal } \\
\text { injection } \\
\text { 1. Vancomycin, } \\
\text { ceftazidime }\end{array}$ & $\begin{array}{l}\text { Count } \\
\text { fingers }\end{array}$ \\
\hline 4 & $\begin{array}{l}\text { Sphingomonas } \\
\text { paucimobilis }\end{array}$ & 2001 & Post-cataract surgery & Yes & $>64$ & $\begin{array}{l}\text { Two intravitreal } \\
\text { injections } \\
\text { 1. Vancomycin, } \\
\text { ceftazidime } \\
\text { 2. Vancomycin, } \\
\text { ceftazidime }\end{array}$ & $6 / 36$ \\
\hline $5^{\ddagger}$ & $\begin{array}{l}\text { Pseudomonas } \\
\text { aeruginosa }\end{array}$ & 2009 & $\begin{array}{l}\text { Endogenous } \\
\text { endophthalmitis - } \\
\text { immunocompromised } \\
\text { patient with cystic }\end{array}$ & Yes & Unavailable & $\begin{array}{l}\text { Two intravitreal } \\
\text { injections, bilaterally } \\
\text { 1. Ceftazidime, } \\
\text { vancomycin, }\end{array}$ & $\begin{array}{l}\text { Right: Hand } \\
\text { movements } \\
\text { Left: } \\
\text { Evisceration }\end{array}$ \\
\hline
\end{tabular}

This article is protected by copyright. All rights reserved. 


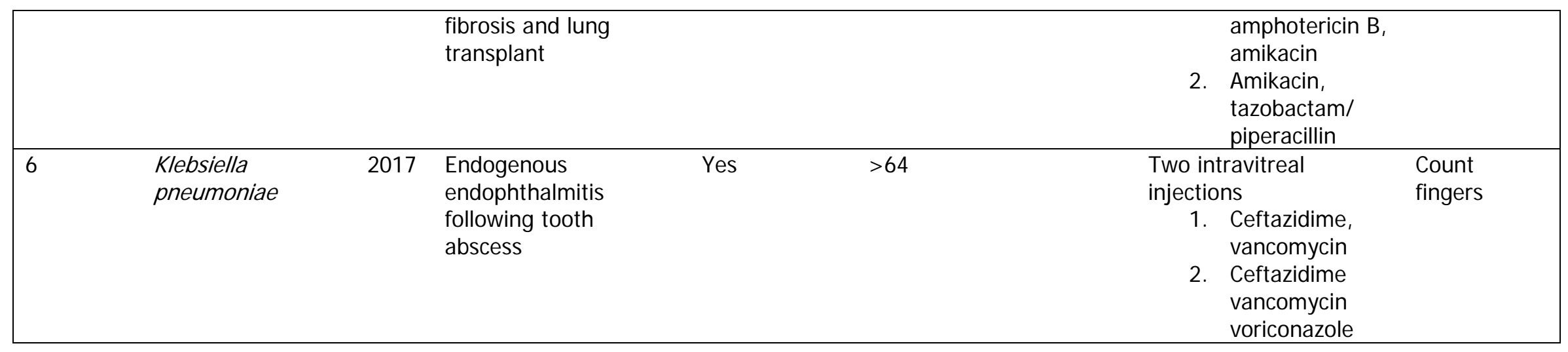

\section{† Denotes polymicrobial infection}

₹ Denotes bilateral case 
The precipitating events or clinical risk factors predisposing to the development of endophthalmitis are summarised for each eye in Table 6. Microbial keratitis was the most common precipitating event $(26.8 \%, \mathrm{n}=26)$, followed by glaucoma surgery $(24.7 \%, n=24)$, cataract surgery $(22.7 \%, n=22)$ and endogenous infection $(15.5 \%, n=15)$. One ( $1.0 \%)$ eye was associated with two risk factors; microbial keratitis and previous glaucoma surgery.

In addition to the case of bilateral Pseudomonas aeruginosa endophthalmitis detailed in Table 5, 1 case of bilateral Haemophilus influenzae infection occurred in a patient with bilateral trabeculectomies.

Table 6: Summary of gram-negative endophthalmitis by precipitating event

\begin{tabular}{|l|c|c|}
\hline Precipitating event & $\begin{array}{c}\mathrm{n}(\%) \text { of Gram- } \\
\text { negative } \\
\text { endophthalmitis cases } \\
\text { by precipitating event }\end{array}$ & $\begin{array}{c}\mathrm{n}(\%) \text { of endophthalmitis cases } \\
\text { secondary to Gram-negative } \\
\text { infection by precipitating event }\end{array}$ \\
\hline Microbial keratitis & $26(26.8)$ & $91(28.6)$ \\
\hline Glaucoma surgery & $24(24.7)$ & $109(22.0)$ \\
\hline Cataract Surgery & $22(22.7)$ & $475(4.6)$ \\
\hline Endogenous infection & $15(15.5)$ & $135(11.1)$ \\
\hline Penetrating ocular trauma & $6(6.2)$ & $70(8.6)$ \\
\hline $\begin{array}{l}\text { Other intraocular } \\
\text { procedures }\end{array}$ & $3(3.1)$ & $58(5.2)$ \\
\hline Intravitreal injections & $2(2.1)$ & $131(1.5)$ \\
\hline
\end{tabular}

At presentation, the fundus was not visible in 81 (83.5\%) eyes and $13(13.7 \%)$ patients had a relative afferent pupillary defect. Nineteen patients (20.0\%) were diabetic, 2 (10.5\%) of whom were on insulin.

VA at presentation and follow-up was available for 93 (95.9\%) and 86 (88.7\%) eyes, respectively. Of the 4 (4.1\%) eyes with missing presenting VA data, $3(3.1 \%)$ 
patients had dementia and 1 (1.0\%) was intubated on admission, preventing their VA from being recorded. The mean time interval from discharge to follow-up was 7.9 months (range $=5$ days -3.9 years). Six (6.3\%) patients had a follow-up period of less than 28 days (mean 13.3 days, range 5 - 23 days) as five (5.3\%) were discharged to private practitioners with no additional data available and $1(1.1 \%)$ was lost to follow up.

At presentation and follow-up, VA was count fingers (CF) or worse in 83 (85.6\%) and 65 (67.0\%) eyes, respectively. These findings are summarised in Table 7. Thirty-five percent of eyes reached a final visual acuity of $6 / 60$ or better following infection precipitated by glaucoma surgery in comparison with $18 \%$ following all other causes; however, this was not statistically significant $(p=0.086)$. The median follow-up VA following microbial keratitis related endophthalmitis was light perception (LP) compared to hand movements (HM) for non-keratitis related infections $(p<0.001)$.

Clinical risk factors associated with poor visual outcomes (VA <6/60) were: no fundus visibility on presentation ( $O R=0.15, p=0.004)$, preceding cataract surgery $(\mathrm{OR}=0.21, \mathrm{p}=0.005)$ or microbial keratitis $(\mathrm{OR}=13.16, \mathrm{p}=0.015)$, and infection secondary to Pseudomonas aeruginosa $(\mathrm{OR}=3.40, \mathrm{p}=0.045)$ or Moraxella spp. $(\mathrm{OR}=0.14, \mathrm{p}=0.001)$. Thirteen ( $13.4 \%)$ eyes managed acutely with a vitrectomy. There was no association between vitrectomy and presenting or final visual acuity.

Table 7: Visual acuity (VA) at presentation and final review

\begin{tabular}{|lll|}
\hline & $\begin{array}{l}\text { VA at presentation } \mathrm{n} \\
(\%)\end{array}$ & VA at final review $\mathrm{n}(\%)$ \\
\hline Evisceration/Enucleation & - & $29(29.9)$ \\
\hline No light perception & $10(10.3)$ & $9(9.3)$ \\
\hline
\end{tabular}




\begin{tabular}{|lll|}
\hline Perception of light & $38(39.2)$ & $6(6.2)$ \\
\hline Hand movements & $32(33.0)$ & $13(13.4)$ \\
\hline Count Fingers & $3(3.1)$ & $8(8.2)$ \\
\hline $6 / 60$ & $2(2.1)$ & $1(1.0)$ \\
\hline $6 / 36$ & $1(1.0)$ & $3(3.1)$ \\
\hline $6 / 24$ & $2(2.1)$ & $1(1.0)$ \\
\hline $6 / 19$ & $3(3.1)$ & $2(2.1)$ \\
\hline $6 / 12$ & $1(1.0)$ & $6(6.2)$ \\
\hline $6 / 9$ & $1(1.0)$ & $3(3.1)$ \\
\hline $6 / 6$ & - & $5(5.2)$ \\
\hline Unavailable & $4(4.1)$ & $11(11.3)$ \\
\hline
\end{tabular}

\section{DISCUSSION}

The time critical nature of endophthalmitis mandates empirical treatment with broad spectrum intravitreal antibiotics. At our institution, intravitreal vancomycin and ceftazidime are administered to provide Gram-positive and Gram-negative coverage, respectively. ${ }^{13}$ Eight (8.0\%) isolates in this series were resistant to third-generation cephalosporins and were therefore resistant to our intravitreal management protocol.

Designing a treatment protocol that is effective against all pathogens identified in this series is a challenge however, due to the infrequent isolation of resistant organisms and their antibiotic resistance profiles. For example, Stenotrophomonas maltophilia is known to have high levels of intrinsic resistance to a wide range of antibiotics, including beta-lactams, quinolones, and aminoglycosides. ${ }^{14}$ However, this is a rare cause of endophthalmitis (only 1 case in our series).

Standard laboratory sensitivity reporting (in Australia most laboratories use Clinical and Laboratory Standards Institute or European Committee on Antimicrobial Susceptibility Testing guidelines) classifies organisms as resistant or sensitive to a particular antibiotic depending on clinical breakpoints based on the minimum 
inhibitory concentration (MIC). The outcome is based on expected serum concentrations achieved with intravenous or oral administration. However, intravitreal injection of antibiotics achieves intraocular concentrations far in excess of the MIC or those reached in the serum following intravenous injection. As such, it is possible that some organisms classified as third-generation cephalosporin resistant, clinically responded to intravitreal ceftazidime. For example, $2 \mathrm{mg}$ of ceftazidime administered into a vitreous chamber of $4 \mathrm{~mL}^{15}$ yields a concentration of $500 \mathrm{mg} / \mathrm{L}$, a value that is significantly higher than the $\mathrm{MIC}$ for most organisms, except Stenotrophomonas maltophilia which is intrinsically resistant. This is supported by the lack of association between antibiotic resistance and visual outcome identified in this analysis.

Seven of 8 third-generation cephalosporin resistant organisms were sensitive to ciprofloxacin. This finding supports the use of oral ciprofloxacin in the empirical management of bacterial endophthalmitis, given it has good vitreous penetration ${ }^{16}$ and almost $90 \%$ of isolates resistant to our intravitreal antibiotic protocol were susceptible to it. However, other than the Endophthalmitis Vitrectomy Study, which investigated the use of intravenous ceftazidime and amikacin, ${ }^{17}$ no randomised controlled trials have evaluated the use of systemic antibiotics in exogenous endophthalmitis, and therefore the efficacy of oral ciprofloxacin is uncertain. ${ }^{18}$

Cases involving third-generation cephalosporin resistant organisms presented between 1997 and 2017, and as such, no trend towards increasing antibiotic resistance was observed. These findings mirror those reported in a Queenslandbased study, which found 30/30 Gram-negative organisms, isolated between 1998 and 2013 , were sensitive to ceftazidime. ${ }^{2}$ There are insufficient data pertaining to other regions of Australia to make comment about emerging resistance elsewhere, highlighting the ongoing need for locally specific research. 
While it is reassuring that no evidence of increasing antibiotic resistance was observed in this series, a degree of caution is warranted when interpreting the significance of this finding. There is strong evidence to indicate that antibiotic resistance is a significant issue internationally, with an Indian study finding 56 of 139 (40.3\%) Gram-negative isolates, presenting between 2010 and 2014, were ceftazidime resistant. ${ }^{6}$ Additionally, at our institution Gram-negative endophthalmitis affects less than 5 patients per year, with Pseudomonas aeruginosa, the most commonly isolated pathogen, affecting less than 2 patients per year. Gram-negative endophthalmitis is therefore a rare event, and the sample size contained within this study too small to confidently conclude that antibiotic resistance is not an increasing issue within Victoria.

Given that antibiotic resistance is an increasing problem throughout all areas of medicine, ${ }^{11}$ including ophthalmology, ophthalmologists must remain vigilant. Furthermore, this highlights the value of capturing data prospectively so that emergent trends can be detected early.

Over the 20-year study period, Gram-negative organisms were isolated in $9.3 \%$ of all endophthalmitis cases at our institution. Within our population, Gram-negative infection represented a significantly smaller proportion of total endophthalmitis cases than has been reported elsewhere. In comparison, three United States-based studies, published in 1992, 2004 and 2013 found Gram-negative organisms were isolated in $18.5 \%{ }^{12}, 11.8 \%{ }^{19}$ and $10.7 \%^{4}$ of endophthalmitis cases, respectively. Similarly, two studies originating from New Zealand and India, published in 2008 and 2009 , found Gram-negative bacteria were isolated in $18.2 \%{ }^{20}$ and $23.9 \%{ }^{5}$ of endophthalmitis cases, respectively. This finding supports the notion that there is significant regional variation in the microbiology of endophthalmitis and emphasises 
the need for local research to accurately characterise disease patterns and microbiology.

In our series, microbial keratitis was the most common precipitating event, preceding more than $25 \%$ of cases. These results confirm the clinical significance of microbial keratitis as a risk factor for the development of Gram-negative endophthalmitis. ${ }^{21}$ This figure is significantly higher than that reported by I rvine et al. who found that 2 of 53 (3.8\%) Gram-negative endophthalmitis cases were keratitis related. ${ }^{12}$ Similarly, Dave et al. found that only 1 of $56(1.8 \%)$ ceftazidime resistant, Gram-negative endophthalmitis cases occurred secondary to corneal ulceration. ${ }^{6}$ I vine et al. included only those cases with positive vitreous or aqueous samples, in comparison to our study that included 14 keratitis-related cases that lacked positive intraocular cultures. If the methodology of I rvine et al. was adopted, microbial keratitis would be the fourth most common precipitating event in this series, affecting $14.5 \%$ of eyes. As such, the observed difference between our study and I vine et al. in part reflects a difference in methodology.

As the Royal Victorian Eye and Ear Hospital is an ophthalmic institution, it is possible that this data base is biased towards non-endogenous causes of endophthalmitis, due to the lack of facilities available for managing systemically unwell patients. Furthermore, counting bilateral cases as distinct for the purpose of organism identification has the effect of inflating the prevalence of the organisms involved in these instances. The effect of this is however negligible and does not meaningfully change the overall results regarding the frequency of organisms isolated in this series.

Multiple studies have reported poor visual outcomes in patients with keratitis-related endophthalmitis, particularly in those with multiple ocular co-morbidities or complex 
past ocular histories. ${ }^{21-23}$ Of the 26 eyes with keratitis related endophthalmitis in this series, 20 (76.9\%) were eviscerated or enucleated in comparison to an evisceration/enucleation rate of $12.7 \%$ for all other eyes. This highlights the extremely poor visual outcomes for this cohort. A number of factors associated with microbial keratitis may contribute to poorer visual outcomes in this cohort including corneal scarring and perforation and difficulty performing vitrectomy where the anterior segment is disrupted.

Visual outcomes for the cohort remained poor overall however, with only $21.6 \%$ of eyes obtaining a final vision of $6 / 60$ or better. This is significantly worse than postcataract endophthalmitis patients in Perth, Western Australia, where only one-third of patients had a visual acuity worse than $6 / 18$ after 6 -months, ${ }^{24}$ or the Endophthalmitis Vitrectomy Study, where 69\% of participants had 6/30 vision or better at 3-months. ${ }^{17}$ Furthermore, these outcomes are significantly worse than those reported from India, where only $16 \%$ of eyes with ceftazidime resistant Gramnegative endophthalmitis had a final VA of no perception of light. ${ }^{6}$

\section{Acknowledgements}

The authors would like to thank all who are involved in maintaining the Victorian Endophthalmitis Registry, without which this study would not have been possible. 


\section{REFERENCES}

1. Gupta A, Orlans HO, Hornby SJ, Bowler ICJ W. Microbiology and visual outcomes of culture-positive bacterial endophthalmitis in Oxford, UK. Graefes Arch Clin Exp Ophthalmol. 2014;252(11):1825-30.

2. Moloney TP, Park J. Microbiological isolates and antibiotic sensitivities in culture-proven endophthalmitis: a 15-year review. Br J Ophthalmol. 2014;98(11):1492-7.

3. Liu C, Ji J, Li S, Wang Z, Tang L, Cao W, et al. Microbiological Isolates and Antibiotic Susceptibilities: A 10-Year Review of Culture- Proven Endophthalmitis Cases. Curr Eye Res. 2016;42(3):443-7.

4. Schimel AM, Miller D, Flynn J r HW. Endophthalmitis isolates and antibiotic susceptibilities: a 10-year review of culture-proven cases. Am J Ophthalmol. 2013;156(1):50-2. e1.

5. Fan J C, Niederer RL, Von Lany H, Polkinghorne PJ. Infectious endophthalmitis: clinical features, management and visual outcomes. Clin Exp Ophthalmol. 2008;36(7):631-6.

6. Dave VP, Pathengay A, Nishant K, Pappuru RR, Sharma S, Sharma P, et al. Clinical presentations, risk factors and outcomes of ceftazidime-resistant Gram negative endophthalmitis. Clin Exp Ophthalmol. 2017;45(3):254-60.

7. Lemley CA, Han DP. Endophthalmitis: a review of current evaluation and management. Retina. 2007;27(6):662-80.

8. Chee S-P, Jap A. Endogenous endophthalmitis. Curr Opin Ophthalmol. 2001;12(6):464-70.

9. Endophthalmitis Vitrectomy Study Group. Microbiologic factors and visual outcome in the endophthalmitis vitrectomy study. AmJ Ophthalmol. 1996;122(6): 830-46. 
10. Jackson TL, Paraskevopoulos T, Georgalas I. Systematic review of 342 cases of endogenous bacterial endophthalmitis. Surv Ophthalmol. 2014;59(6):627-35.

11. Ventola CL. The antibiotic resistance crisis: part 1: causes and threats. P T. 2015;40(4):277.

12. I rvine WD, Flynn HW, Miller D, Pflugfelder SC. Endophthalmitis caused by gram-negative organisms. Arch Ophthalmol. 1992;110(10):1450-4.

13. Schwartz SG, Flynn J r HW. Update on the prevention and treatment of endophthalmitis. Expert Rev Ophthalmol. 2014;9(5):425-30.

14. Brooke JS, Di Bonaventura G, Berg G, Martinez J-L. A multidisciplinary look at Stenotrophomonas maltophilia: An emerging multi-drug-resistant global opportunistic pathogen. Front Microbiol. 2017;8:1511.

15. Dorairaj S, Liebmann JM, Tello C, Barocas V, Ritch R. Posterior chamber volume does not change significantly during dilation. Br J Ophthalmol. 2009.

16. Lesk MR, Ammann H, Marcil G, Vinet B, Lamer L, Sebag M. The penetration of oral ciprofloxacin into the aqueous humor, vitreous, and subretinal fluid of humans. AmJ Ophthalmol. 1993; 115(5):623-8.

17. J ohnson MW, Daft BH, Kelsey SF, Barza M, Wilson LA, Barr CC, et al. The Endophthalmitis Vitrectomy Study. Ophthalmology. 1997;104(2):261-72.

18. Durand ML. Bacterial and Fungal Endophthalmitis. Clin Microbiol Rev. 2017;30(3):597-613.

19. Benz MS, Scott IU, Flynn J r HW, Unonius N, Miller D. Endophthalmitis isolates and antibiotic sensitivities: a 6-year review of culture-proven cases. Am J Ophthalmol. 2004;137(1):38-42.

20. Ramakrishnan R, Bharathi MJ, Shivkumar C, Mittal S, Meenakshi R, Khadeer MA, et al. Microbiological profile of culture-proven cases of exogenous and endogenous endophthalmitis: a 10-year retrospective study. Eye (Lond). 2009;23(4):945-56. 
21. Henry CR, Flynn J r HW, Miller D, Forster RK, Alfonso EC. Infectious keratitis progressing to endophthalmitis: a 15-year study of microbiology, associated factors, and clinical outcomes. Ophthalmology. 2012;119(12):2443-9.

22. Malihi M, Li X, Patel S, Eck T, Chu DS, Zarbin MA, et al. Infectious Keratitisassociated Endophthalmitis: A 14-year Study. Retina. 2017;37(4):662-6.

23. O'Neill EC, Yeoh J, Fabinyi DC, Cassidy D, Vajpayee RB, Allen P, et al. Risk factors, microbial profiles and prognosis of microbial keratitis-associated endophthalmitis in high-risk eyes. Graefes Arch Clin Exp Ophthalmol. 2014;252(9): 1457-62.

24. Ng J Q, Morlet N, Pearman J W, Constable IJ, McAllister IL, Kennedy C, et al. Management and outcomes of postoperative endophthalmitis since the endophthalmitis vitrectomy study: the Endophthalmitis Population Study of Western Australia (EPSWA)'s fifth report. Ophthalmology. 2005;112(7):1199-206. e2. 


\section{University Library}

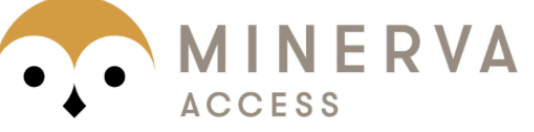

A gateway to Melbourne's research publications

Minerva Access is the Institutional Repository of The University of Melbourne

Author/s:

Stevenson, LJ;Dawkins, RCH;Sheorey, H;McGuinness, MB;Hurley, AH;Allen, PJ

Title:

Gram-negative endophthalmitis: A prospective study examining the microbiology, clinical associations and visual outcomes following infection

Date:

2020-05-11

Citation:

Stevenson, L. J., Dawkins, R. C. H., Sheorey, H., McGuinness, M. B., Hurley, A. H. \& Allen, P. J. (2020). Gram-negative endophthalmitis: A prospective study examining the microbiology, clinical associations and visual outcomes following infection. CLINICAL AND EXPERIMENTAL OPHTHALMOLOGY, 48 (6), pp.813-820. https://doi.org/10.1111/ceo.13768.

Persistent Link:

http://hdl.handle.net/11343/275737 